\title{
Lipomatous angiomyofibroblastoma of the vulva: A case report and review of the literature
}

\author{
SUSUMU MATSUKUMA $^{1,2}$, AYANO KOGA ${ }^{1}$, RYOHEI SUEMATSU ${ }^{1}$, HIROAKI TAKEO $^{1}$ and KIMIYA SATO ${ }^{1}$ \\ ${ }^{1}$ Department of Pathology and ${ }^{2}$ Health Care Center, Japan Self-Defense Forces Central Hospital, Tokyo 154-8532, Japan
}

Received July 4, 2016; Accepted August 18, 2016

DOI: $10.3892 / \mathrm{mco} .2016 .1078$

\begin{abstract}
Lipomatous angiomyofibroblastoma is extremely rare, with only 16 cases reported to date. We herein describe an additional case arising in the left vulvar region of a 49-year-old woman. The resected $5.3-\mathrm{cm}$ yellowish tumor predominantly consisted of fat cells ( $85 \%$ of the tumor), together with medium- and small-sized vessels, multifocal fibrotic areas and pseudoangiomatous spaces. Spindle, rounded, and/or epithelioid tumor cells proliferated in a nest and/or cord-like pattern, or singly within perivascular fibrous tissues and between fat cells. The tumor cells were positive for vimentin, estrogen receptor, progesterone receptor, B-cell lymphoma 2, and CD10, but were negative for desmin, cytokeratin, epithelial membrane antigen, S-100 protein, human melanoma black 45, C-kit and p40. Ultrastructural examination revealed that these tumor cells exhibited fibroblastic characteristics. Lipomatous angiomyofibroblastoma should be discriminated from other lipomatous tumors, including spindle cell lipoma, angiomyolipoma and cellular angiofibroma containing numerous fat cells.
\end{abstract}

\section{Introduction}

Angiomyofibroblastoma (AMF) is an uncommon, benign neoplasm that most commonly involves the vulvovaginal region and may contain scattered fat cells (1-4). However, AMFs with a prominent fatty component are extremely rare. To the best of our knowledge, only 16 cases have been reported in the English literature to date (5-15), and such tumors have been referred to as 'lipomatous variants of AMF' $(2,6,9-11,14,15)$, which was first termed by Laskin et al (6), or 'lipomatous AMF' $(7,12,13)$. We herein present another pertinent case to expand our understanding of lipomatous AMF.

Correspondence to: Dr Susumu Matsukuma, Department of Pathology, Japan Self-Defense Forces Central Hospital, 1-2-24 Ikejiri, Setagaya-ku, Tokyo 154-8532, Japan

E-mail: skuma@cocoa.plala.or.jp

Abbreviations: AMF, angiomyofibroblastoma; ER, estrogen receptor; PgR, progesterone receptor; EMA, epithelial membrane antigen

Key words: angiomyofibroblastoma, lipomatous, vulva, spindle cell lipoma, cellular angiofibroma

\section{Case report}

A 49-year-old woman presented to the Japan Self-Defense Forces Central Hospital (Tokyo, Japan) with a 4-cm, left vulvar mass and mild associated tenderness. The tumor had been slowly increasing in size for 1.3 years. Magnetic resonance imaging examination revealed a benign lipomatous vulvar tumor, a 7.5-cm uterine leiomyoma and a 1-cm hepatic hemangioma. No other tumors were found and the serum laboratory data were normal. The patient underwent simple hysterectomy for uterine leiomyoma and resection of the vulvar mass and was discharged 1 month after the surgery without complications.

The removed vulvar tumor was a well-demarcated, yellowish, solid mass, measuring $5.3 \times 3 \times 2.8 \mathrm{~cm}$ (Fig. 1). Histologically, the tumor consisted of equally distributed abundant fat cells involving $\sim 85 \%$ of the tumor, numerous medium- to small-sized vessels, multifocal fibrous areas and pseudoangiomatous spaces without cellular lining (Fig. 2A). No fibrous capsule or hypocellular myxoid areas were observed. Spindle, rounded, or epithelioid tumor cells with mildly hyperchromatic ovoid nuclei proliferated in small nests and/or cords, or singly within the perivascular fibrous tissue of both fatty and fibrous areas (Fig. 2B), occasionally adjacent to the pseudoangiomatous spaces. Similar neoplastic cells were also singly scattered between fat cells (Fig. 2C), although they were inconspicuous on low-power magnification. Binucleated tumor cells were occasionally seen. Mitotic figures were absent. A small number of vacuolated cells (Fig. 2D) were present neighboring to tumor cells, but lipoblasts were not identified. Mast cells were also present near the tumor cells. Immunohistochemically, the tumor cells were diffusely positive for vimentin, estrogen receptor (ER) and CD10, but ER-negative and/or CD10-negative tumor cells were also identified. The tumor cells were focally and weakly positive for progesterone receptor (PgR) and B-cell lymphoma 2 (Bcl-2), but were negative for desmin, cytokeratin, epithelial membrane antigen (EMA), S-100 protein, human melanoma black 45 (HMB45), C-kit and p40. Ultrastructurally, the tumor cells were joined to adjacent tumor cells without distinct junctional structures. The cytoplasm of the tumor cells was relatively scarce, but contained rough endoplasmic reticulum, intermediate filaments, mitochondria, pinocytotic vesicles (Fig. 3) and Golgi apparatus. There were no convincing transitional characteristics between tumor and fat cells. 


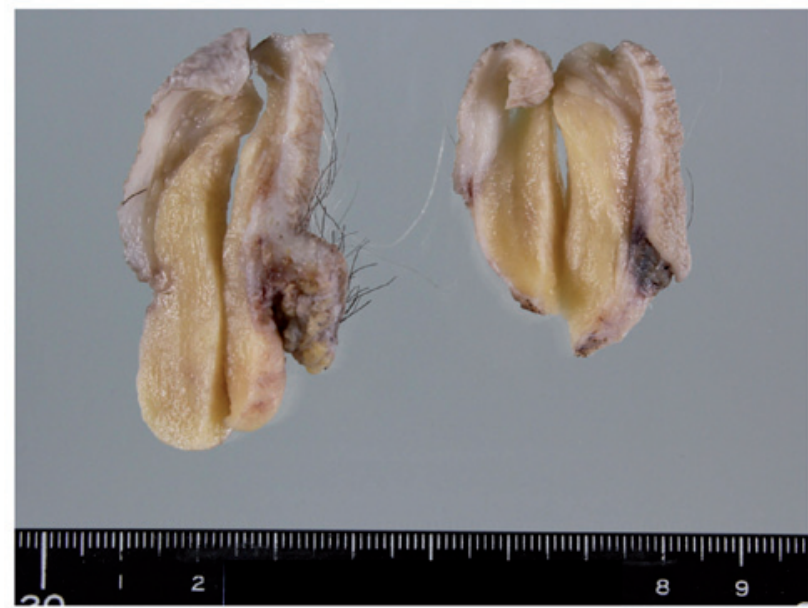

Figure 1. On cross-section, the vulvar tumor appeared to be yellowish, well-demarcated and solid.
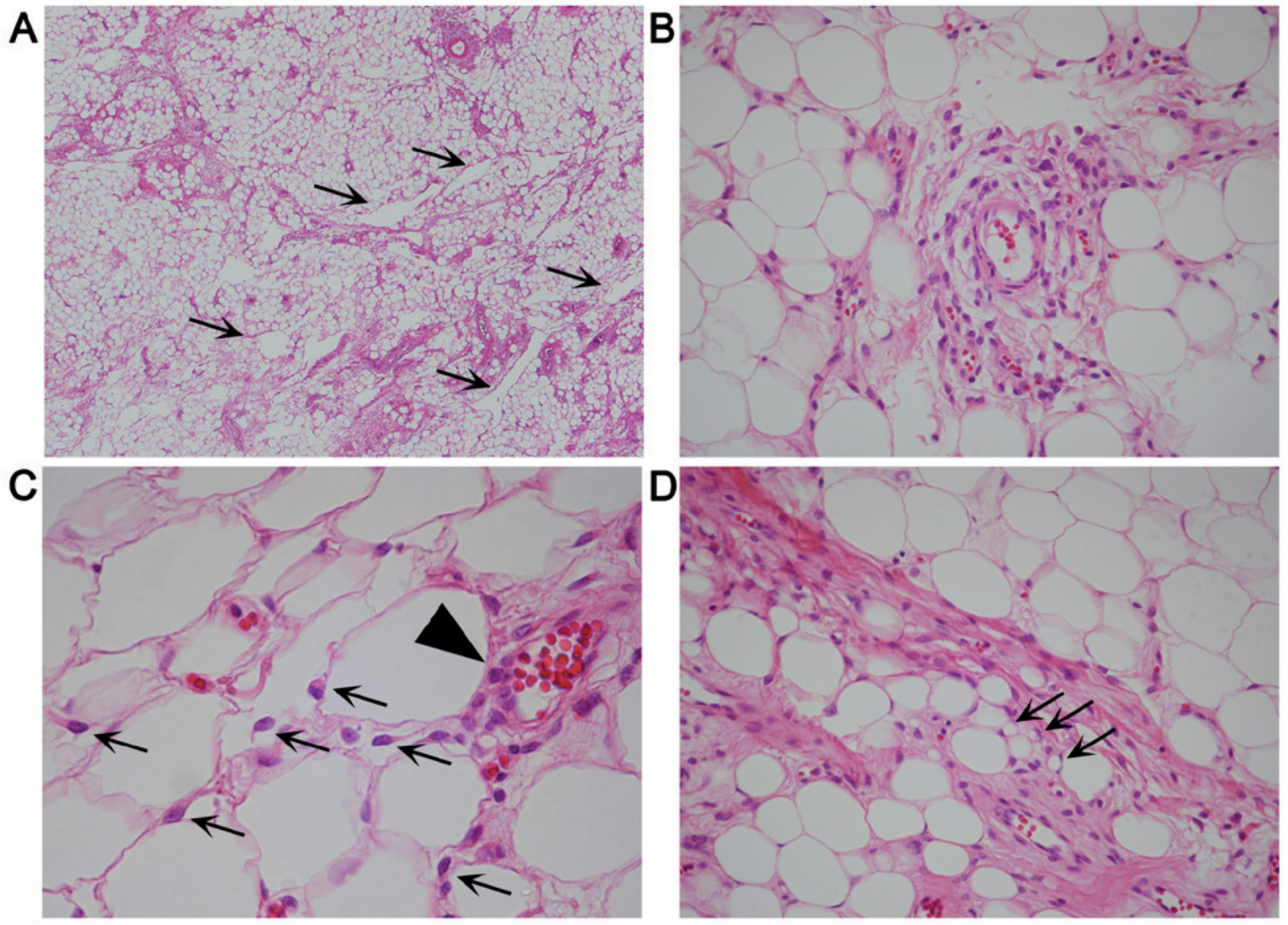

Figure 2. Hematoxylin and eosin-stained sections of lipomatous angiomyofibroblastoma. (A) Low-power magnification (x40) showing numerous fat cells, together with medium-sized vessels and pseudoangiomatous spaces (arrows). (B) Spindle and rounded tumor cells proliferating singly or in clusters in perivascular fibrotic areas (magnification, x400). (C) Spindle or epithelioid neoplastic cells (arrows) scattered singly between fat cells and in a nest-like pattern around a vessel (arrowhead) (magnification, x600). (D) A few vacuolated cells (arrows) were identified near the tumor and fat cells (magnification, x400).

\section{Discussion}

The present tumor was rich in fat cells, and singly scattered neoplastic cells between the fat cells were difficult to detect. However, nest- or cord-like growth of rounded and/or epithelioid tumor cells was identified, mostly in the perivascular fibrous tissue. Ultrastructurally, the tumor cells displayed fibroblastic characteristics. These findings are consistent with those of typical AMF (1-6), and the tumor was diagnosed as lipomatous AMF. In the present case, pseudoangiomatous characteristics were observed throughout the tumor, which have not been mentioned in previous reports of lipomatous AMF (5-15). However, similar characteristics are known to occur in AMF and spindle cell lipoma $(1,2)$. 


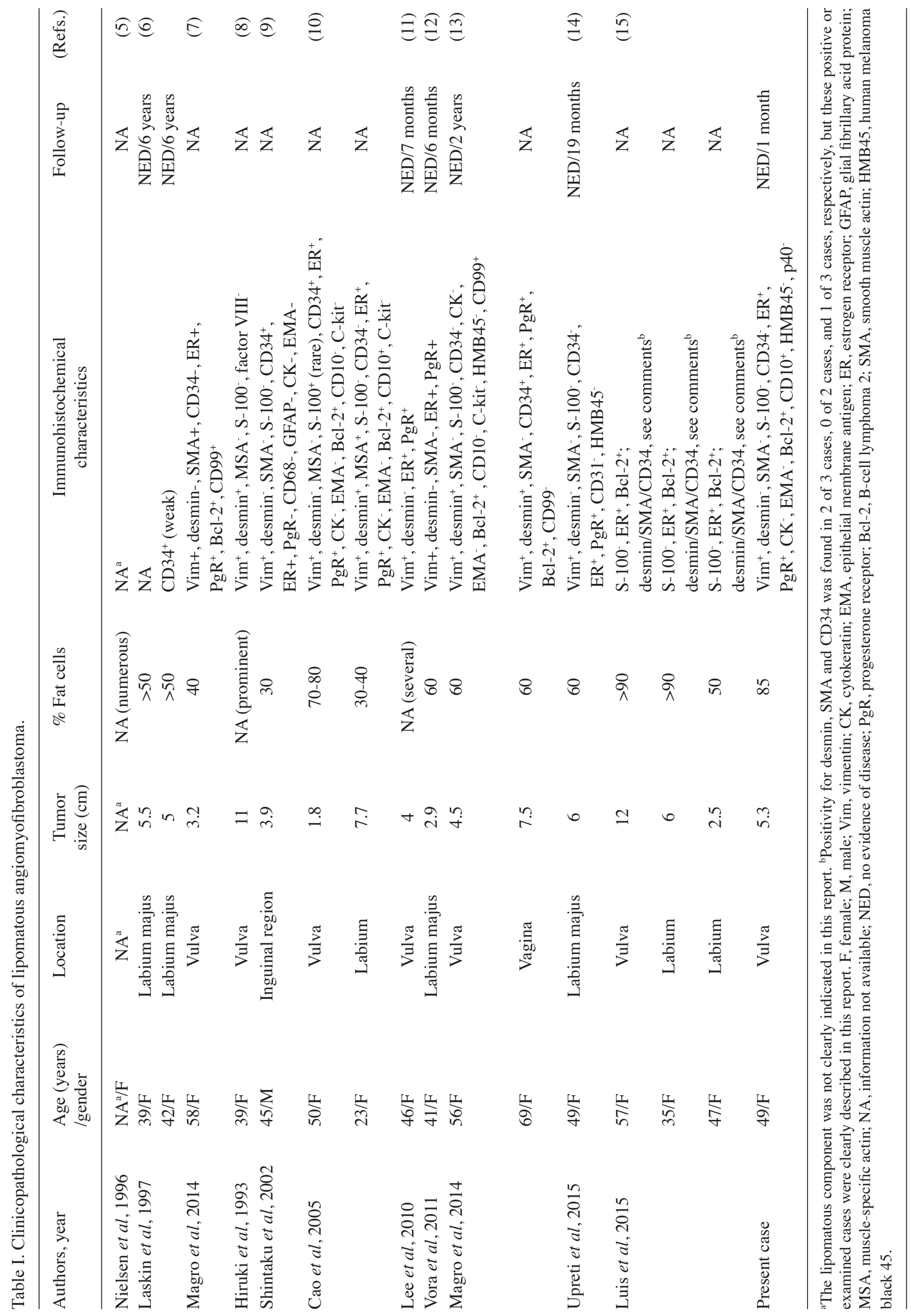




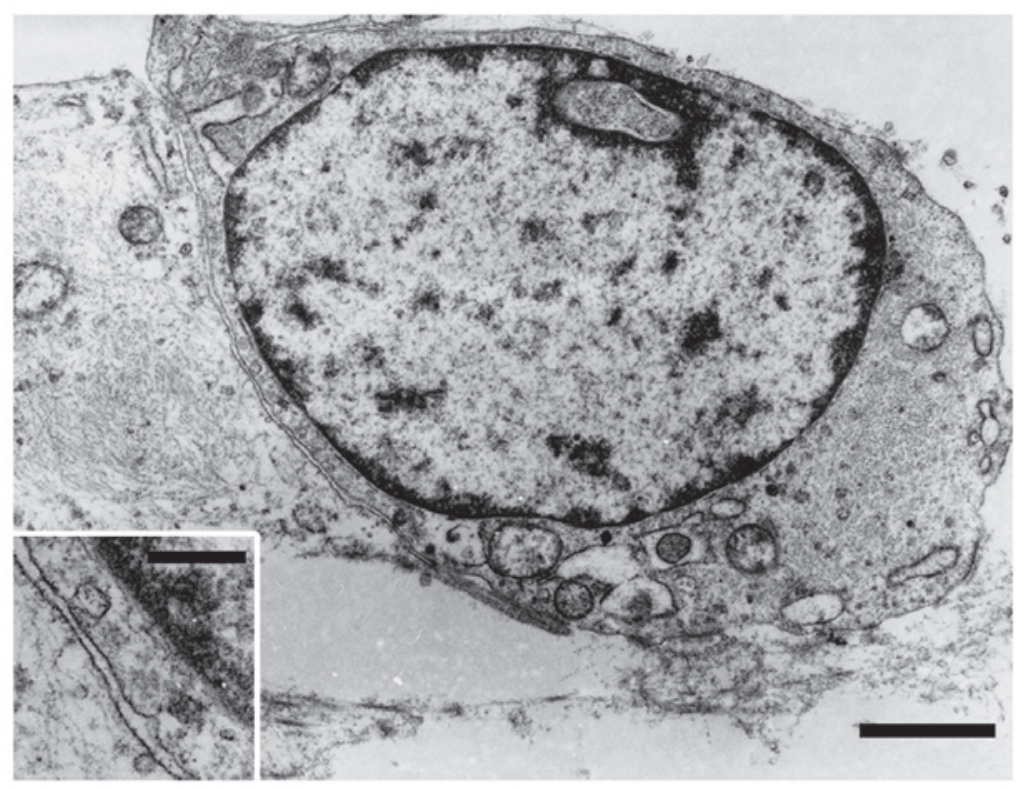

Figure 3. Ultrastructural characteristics of adjoining tumor cells showing intermediate filaments, dilated cisternae of the rough endoplasmic reticulum, mitochondria and pinocytotic vesicles; uranyl acetate and lead citrate staining; bar, $1.5 \mu \mathrm{m}$ (inset depicting pinocytotic vesicles; bar, $300 \mathrm{~nm}$ ).

The clinicopathological characteristics of previously reported cases of lipomatous AMF (5-15) and the present case are summarized in Table I. The fatty component ranged from 30 to $>90 \%$ of the tumor, apart from 3 cases where the fatty proportion was not mentioned. Therefore, the term 'lipomatous' AMF may be used when the fat cells constitute $\geq 30 \%$ of the tumor. The tumor size and the patient age ranged from 1.8 to $11 \mathrm{~cm}$ (mean, $5.6 \mathrm{~cm}$ ) and from 23 to 69 years (mean, 46.6 years), respectively. Aggressive behavior has not been reported. Sarcomatous characteristics have rarely been reported in AMF (16), but never in lipomatous AMF. Immunohistochemically, the tumor cells were positive for vimentin (11/11), ER (12/12), Bcl-2 (9/9), PgR (8/9), CD34 (5/12), desmin (6/14), CD10 (2/4), CD99 (2/3), muscle-specific actin (1/3), smooth muscle actin (1/9) and S-100 protein (1/10), and negative for cytokeratin (0/5), EMA (0/5), C-kit (0/4), HMB45 (0/3), glial fibrillary acidic protein $(0 / 1)$, CD68 (0/1) and factor VIII (0/1). In AMF, the tumor cells are strongly and diffusely positive for desmin, although such positivity may be reduced or absent in postmenopausal patients (1). However, excluding cases without distinct information, no desmin reactivity was observed in $5(71 \%)$ of 7 patients with lipomatous AMF aged $<50$ years $(8-12,14)$, which was unlike the typical AMF characteristics. In the present case, the tumor cells were also negative for desmin, and the cytoplasmic intermediate filaments were considered to be vimentin.

Differential diagnosis of lipomatous AMF includes spindle cell lipoma, angiomyolipoma and cellular angiofibroma. Proliferating spindle cells and pseudoangiomatous characteristics in spindle cell lipoma are similar to those of lipomatous AMF. However, these tumor cells are usually spindle-shaped only, and do not form nests. ER positivity has not been reported in spindle cell lipoma. Angiomyolipoma consists of fat cells and epithelioid or spindle cells, occasionally in a perivascular arrangement $(1,2)$, which may mimic lipomatous AMF.
However, these epithelioid cells mainly exhibit smooth muscle configuration, do not usually form nests, and are consistently positive for HMB45 $(1,2)$. In addition, the occurrence of spindle cell lipoma and angiomyolipoma in the vulvovaginal region is extremely rare $(1,2,17)$. These characteristics may help distinguish lipomatous AMF from spindle cell lipoma and angiomyolipoma. Cellular angiofibroma was previously referred to as AMF-like tumor in males, and may contain fat cells $(1,2,18)$. Compared with AMF, in cellular angiofibroma, the proliferating cells are primarily spindled, the tumor is more highly cellular, and the proliferating vessels and stroma are more prominently collagenous and/or hyalinized, although the spindle cells in cellular angiofibroma may be positive for ER, PgR, CD34 and desmin (1,2,18-20).

The pathogenesis of lipomatous components within AMF remains controversial. Some investigators have suggested that lipomatous components may be due to adipocytic metaplasia or fatty differentiation of tumor cells (6,7). In the present case, early fatty-like changes in vacuolated cells were observed near the tumor cells. However, there were no convincing transitional characteristics between tumor and fat cells. To elucidate whether fatty differentiation of tumor cells occurs in AMF, further investigation is required.

\section{Acknowledgements}

The authors would like to thank Yoshiko Uchikoshi for excellent assistance and Daniel Mrozek for editing the manuscript.

\section{References}

1. Fletcher CDM, Bridge JA, Hogendoorn PCW and Mertens F (eds): WHO classification of tumours of soft tissue and bone. 4th edition. International Agency for Research on Cancer, Lyon, 2013.

2. Goldblum JR, Folpe AL and Weiss SW (eds): Enzinger and Weiss's soft tissue tumors. 6th edition. Elsevier/Saunders, Philadelphia, PA, 2014. 
3. Fletcher CDM, Tsang WYW, Fisher C, Lee KC and Chan JKC Angiomyofibroblastoma of the vulva. A benign neoplasm distinct from aggressive angiomyxoma. Am J Surg Pathol 16: 373-382, 1992.

4. Hisaoka M, Kouho H, Aoki T, Daimaru Y and Hashimoto H: Angiomyofibroblastoma of the vulva: A clinicopathologic study of seven cases. Pathol Int 45: 487-492, 1995.

5. Nielsen GP, Rosenberg AE, Young RH, Dickersin GR Clement PB and Scully RE: Angiomyofibroblastoma of the vulva and vagina. Mod Pathol 9: 284-291, 1996.

6. Laskin WB, Fetsch JF and Tavassoli FA: Angiomyofibroblastoma of the female genital tract: Analysis of 17 cases including a lipomatous variant. Hum Pathol 28: 1046-1055, 1997.

7. Magro G, Righi A, Caltabiano R, Casorzo L and Michal M: Vulvovaginal angiomyofibroblastomas: Morphologic, immunohistochemical, and fluorescence in situ hybridization analysis for deletion of 13q14 region. Hum Pathol 45: 1647-1655, 2014.

8. Hiruki T, Thomas MJ and Clement PB: Vulvar angiomyofibroblastoma. Am J Surg Pathol 17: 423-424, 1993.

9. Shintaku M, Naitou M and Nakashima Y: Angiomyofibroblastoma-like tumor (lipomatous variant) of the inguinal region of a male patient. Pathol Int 52: 619-622, 2002

10. Cao D, Srodon M, Montgomery EA and Kurman RJ: Lipomatous variant of angiomyofibroblastoma: Report of two cases and review of the literature. Int J Gynecol Pathol 24: 196-200, 2005.

11. Lee SJ, Chung YJ, Lee SH, Choi YJ, Kim N, Son HJ and Yoon JH: Lipomatous variant of angiomyofibroblastoma on the vulva: A case report. Korean J Obstet Gynecol 53: 851-855, 2010

12. Vora S, Gaba ND and Stamatakos MD: Lipomatous angiomyofibroblastoma: A case report of a unique vulvar mass. J Reprod Med 56: 347-350, 2011

13. Magro G, Salvatorelli L, Angelico G, Vecchio GM and Caltabiano R: Lipomatous angiomyofibroblastoma of the vulva: Diagnostic and histogenetic considerations. Pathologica 106: 322-326, 2014
14. Upreti S, Morine A, Ng D and Bigby SM: Lipomatous variant of angiomyofibroblastoma: A case report and review of the literature. J Cutan Pathol 42: 222-226, 2015.

15. Luis PP, Quiñonez E, Nogales FF and McCluggage WG: Lipomatous variant of angiomyofibroblastoma involving the vulva: Report of 3 cases of an extremely rare neoplasm with discussion of the differential diagnosis. Int J Gynecol Pathol 34: 204-207, 2015.

16. Nielsen GP, Young RH, Dickersin GR and Rosenberg AE: Angiomyofibroblastoma of the vulva with sarcomatous transformation ("angiomyofibrosarcoma"). Am J Surg Pathol 21: 1104-1108, 1997.

17. Reis-Filho JS, Milanezi F, Soares MF, Fillus-Neto J and Schmitt FC: Intradermal spindle cell/pleomorphic lipoma of the vulva: Case report and review of the literature. J Cutan Pathol 29: 59-62, 2002

18. LaskinWB,FetschJFandMostofiFK:Angiomyofibroblastomalike tumor of the male genital tract: Analysis of 11 cases with comparison to female angiomyofibroblastoma and spindle cell lipoma. Am J Surg Pathol 22: 6-16, 1998.

19. Iwasa Y and Fletcher CDM: Cellular angiofibroma: Clinicopathologic and immunohistochemical analysis of 51 cases. Am J Surg Pathol 28: 1426-1435, 2004.

20. Flucke U, van Krieken JH and Mentzel T: Cellular angiofibroma: Analysis of 25 cases emphasizing its relationship to spindle cell lipoma and mammary-type myofibroblastoma. Mod Pathol 24: 82-89, 2011 